\title{
Hyperornithinemia-Hyperammonemia- Homocitrullinuria Syndrome: Low Creatine Excretion and Effect of Citrulline, Arginine, or Ornithine Supplement
}

\author{
C. DIONISI VICI, C. BACHMANN, M. GAMBARARA, J. P. COLOMBO, AND G. SABETTA \\ Servizio di Patologia Metabolica, Ospedale Pediatrico Bambino Gesù Istituto per la Ricerca Scientifica, \\ Rome, Italy and Department of Clinical Chemistry, University of Bern, Inselspital, Bern, Switzerland
} [C.B., J.P.C.]

\begin{abstract}
Two patients with neonatal onset of hyperornithinemia-hyperammonemia-homocitrullinuria syndrome were studied at 4 and $2 \frac{1}{2}$ yr of age, respectively. The aim of the investigation was to assess the effect of supplementing citrulline, arginine, or ornithine $(2 \mathrm{mmol} /$ $\mathrm{kg}$ per day) while on a protein-restricted diet. The peroral supplementation was carried out during 2 wk for each aminoacid. While ammonia in plasma was not increased the supply of citrulline or arginine led to a reduction of plasma glutamine compared to ornithine supplement or to no supplement (control period). Plasmatic ornithine was raised in all instances. Homocitrulline excretion was lower with all additions compared to the control period. Adding citrulline to the diet (in contrast to supplementing arginine) did not lower tubular lysine reabsorption. A lowered creatine excretion was found which could be normalized by arginine or citrulline. The data are compatible with a product inhibition of arginino-glycine transamidinase suggesting that the enzyme is not located in the mitochondrial matrix in man. Citrulline supplement combined with a protein-restricted diet appears to allow a normal development. The additional finding of a factor VII and $X$ deficiency in one of the patient and reports in the literature of this association in two other patients with hyperornithinemia-hyperammonemia-homocitrullinuria syndrome suggest that the genetic defect leading to the syndrome might be located on chromosome 13. (Pediatr Res 22: 364-367, 1987)
\end{abstract}

\section{Abbreviations}

HHH, hyperornithinemia-hyperammonemia-homocitrullinuria

OCT, ornithinecarbamoyl transferase

UV, ultraviolet

WPPSI, Wechsler Preschool and Primary Scale of Intelligence

The HHH syndrome is a rare inborn error of aminoacid metabolism first described by Shih et al. in 1969 (1). Up to this point 23 patients have been reported $(1-14)$. Clinical symptoms are vomiting, lethargy, coma, seizures, ataxia, and various de-

Received February 10, 1987; accepted April 29, 1987.

Correspondence and reprint requests Claude Bachmann, M.D., Department of Clinical Chemistry, University of Bern, Inselspital, CH-3010 Bern, Switzerland.

Supported by the Swiss National Science Foundation Grant 3.910.0.85. grees of mental retardation, as observed in other hyperammonemic disorders. Only one patient reported so far (patient B,13) showed symptoms as a neonate.

The molecular basis of the HHH syndrome remains unclear. Several investigators have postulated a specific defect in the transport of ornithine across the inner mitochondrial membrane but a definite proof is still lacking due to controversial results (6, 7, 14-19). Previous reports on therapeutic trials using supplements of ornithine, arginine, lysine or citrulline in patients with HHH syndrome for controlling hyperammonemia and the other metabolic disturbancies (hyperornithinemia, homocitrulline, and orotic acid excretion) led to contradictive results $(1,3,5-$ $10,12-15,19)$. In the present study we assessed the effect of supplementing perorally citrulline, arginine, or ornithine, administered during $2 \mathrm{wk}$ each separately in two unrelated patients with HHH syndrome kept on a protein-restricted diet. The marked variations in the daily excretion of creatine depending on the supplement used is of particular interest.

\section{MATERIALS AND METHODS}

Protocol of treatment and sample collection. Both patients were treated for a 2-wk period respectively with citrulline (C), argininebase (A), and ornithine-base (O) $2 \mathrm{mmol} / \mathrm{kg}$ per day given in two doses perorally with the meals at 4 (patient $A$ ) and $2 \frac{1 / 2}{2}$ (patient B) yr of age. The trials were consecutive in the order shown in Tables 1 and 2 without washout periods. For control the investigations were also performed after a separate 2-wk period without amino acid supplement $(\mathrm{N})$. Before control period patient $\mathrm{A}$ had been on chronic treatment with citrulline while patient B was without any preceeding supplement. During the study the protein supply was kept constant in quality and quantity (1.2 and $1.5 \mathrm{~g} / \mathrm{kg}$ per day, respectively, for patient $\mathrm{A}$ and $\mathrm{B}$ ). Blood samples were drawn at the end of each 2-wk period of treatment (or control) at $0900 \mathrm{~h}$ after an overnight fast $(12 \mathrm{~h}$ after the last meal). A 24-h urine was collected, starting $24 \mathrm{~h}$ before the blood sampling. No side effects were observed with the different protocols of treatment. The parents were informed and consented to the study.

Analytical methods. Samples for the amino acid and orotic acid determinations were frozen at $-20^{\circ} \mathrm{C}$. Amino acids were quantified by ion exchange chromatography (Biotronik 7000 , Munich, FRG) using norvaline as internal standard. Orotic acid in urine was determined by anion exchange chromatography as described (20). Blood ammonia was assayed with an enzymatic UV method (Boehringer, Mannheim, FRG). Creatinine was determined by a kinetic Jaffé reaction and creatine colorimetrically (21). Urea was determined in urine with urease including 
an analytical blank without urease to account for urinary ammonia.

\section{CASE REPORTS}

Both in patients $\mathrm{A}$ and $\mathrm{B}$ the onset of the disease was neonatal. Feeding difficulties, vomiting, hypotonia, and seizures were the predominant symptoms and hyperammonemia was found. ADC (boy), patient $A$, is the third born of two related parents (first cousins). His older sister presents a mild mental retardation not due to an $\mathrm{HHH}$ syndrome. Pregnancy and delivery had been uneventful. At 14 days of life he was admitted to the hospital because of vomiting, hypotonia, and seizures. Biochemical investigations revealed a hyperammonemia $(240 \mu \mathrm{mol} / \mathrm{liter})$ and an increase of serum transaminases (GOT 210 U/liter, GPT 159 $\mathrm{U} /$ liter). The patient was then treated with phenobarbital and kept on a protein intake of $1.8 \mathrm{~g} / \mathrm{kg}$ per day. The diagnosis of the $\mathrm{HHH}$ syndrome was established at $2 \mathrm{yr}$ of age during an intermittent attack of ataxia and lethargy. He was treated with a protein-restricted diet $(1.2 \mathrm{~g} / \mathrm{kg}$ per day), supplemented by citrulline $(2 \mathrm{mmol} / \mathrm{kg}$ per day). At the age of $4 \mathrm{yr}$ weight was 16.5 $\mathrm{kg}$ (50th percentile), height was $103 \mathrm{~cm}$ (50th percentile) and head circumference was $52 \mathrm{~cm}$ (60th percentile). The WPPSI at age of $4 \mathrm{yr}$ and 9 months revealed a full scale IQ of 72 (3rd percentile).

The clinical features of $\mathrm{CD}$ (girl), patient $\mathrm{B}$, have already been reported (13). A neonatal hyperammonemia (283 $\mu \mathrm{mol} / \mathrm{liter})$ was assumed to be due to an OCT deficiency. We detected homocitrullinuria and orotic aciduria at 3 months of age. The patients protein intake was restricted to $1.5-1.8 \mathrm{~g} / \mathrm{kg} /$ day and arginine (later citrulline) supplemented. During a routine hematological investigation, a deficiency of factor VII (21\%) and factor X $(25 \%)$ were additionally found in this patient without manifestation of any clinical symptoms. At $2 \frac{1 / 2}{\mathrm{yr}}$ of age she weighed $13.5 \mathrm{~kg}$ (50th percentile), her height was $88 \mathrm{~cm}$ (25th percentile), and head circumference was $49.5 \mathrm{~cm}$ (60th percentile). The development quotient by Brunet-Lézine testing was 81 (developmental age 32 months at 40). Since the start of the protein-restricted diet we never observed episodes of hyperammonemia. Hyperornithinemia was absent in several instances when checked during the chronic treatment, while homocitrullinuria persisted. The lowest ornithine in plasma $(71 \mu \mathrm{mol} / \mathrm{liter})$ had been found (13) at 28 days of age when the patient was treated with benzoate $(250 \mathrm{mg} / \mathrm{kg}$ per day) and low-protein diet $(0.75 \mathrm{~g} / \mathrm{kg}$ per day).

\section{RESULTS}

Plasma ammonia concentrations remained normal but plasma ornithine values were elevated with all protocols used (Table 1). Homocitrulline excretion was moderately lowered with all three amino acid supplements compared to the control period (Table 2).

In both patients lysine was never low and its rise in plasma was not followed by an increased homocitrulline excretion. In both patients the variations observed in plasma lysine concentration paralleled those of ornithine $(r=0.9540, p<0.001)$. In both patients glutamine was raised when ornithine was added to the diet or during the period without supplement. Ornithine was the only amino acid whose concentration in plasma increased in both patients when added to the diet. The arginine concentration in plasma always exceeded the upper normal range. No seizures were observed.

The fractional tubular reabsorptions (compared to creatinine clearance) of all the amino acids were normal in the absence of supplement. However, it should be noted that the fractional tubular reabsorption of lysine was lower with arginine supplement (patient A: $96.3 \%, \mathrm{~B}: 91.6 \%$ ) than with citrulline substitution $(98.4 \% ; 95.5 \%)$. Without treatment the fractional tubular reabsorptions of lysine were 99.3 and $98.4 \%$, respectively. The daily excretion of creatine (Table 2) was below normal in both patients when no amino acids were added to the diet. This value remained below normal with ornithine supplementation in patient $\mathrm{B}$ while it reached the normal range both in patient $\mathrm{A}$ and $B$ when citrulline and arginine were supplemented.

The pattern of creatine excretion paralleled that of urinary urea (correlation $r=0.9161, p<0.001$; Spearman $\rho=0.857, p$ $<0.02$ ). The excretion of arginine followed a similar pattern. The low creatine excretion was not related to an increased ornithine concentration in plasma.

Table 1. Plasma amino acids, ammonia, and creatinine ( $\mu$ mol/liter) in patients $A$ and $B$ under different protocols of treatment (C), $A, O)^{*}$ and during control period $(N)^{*}$

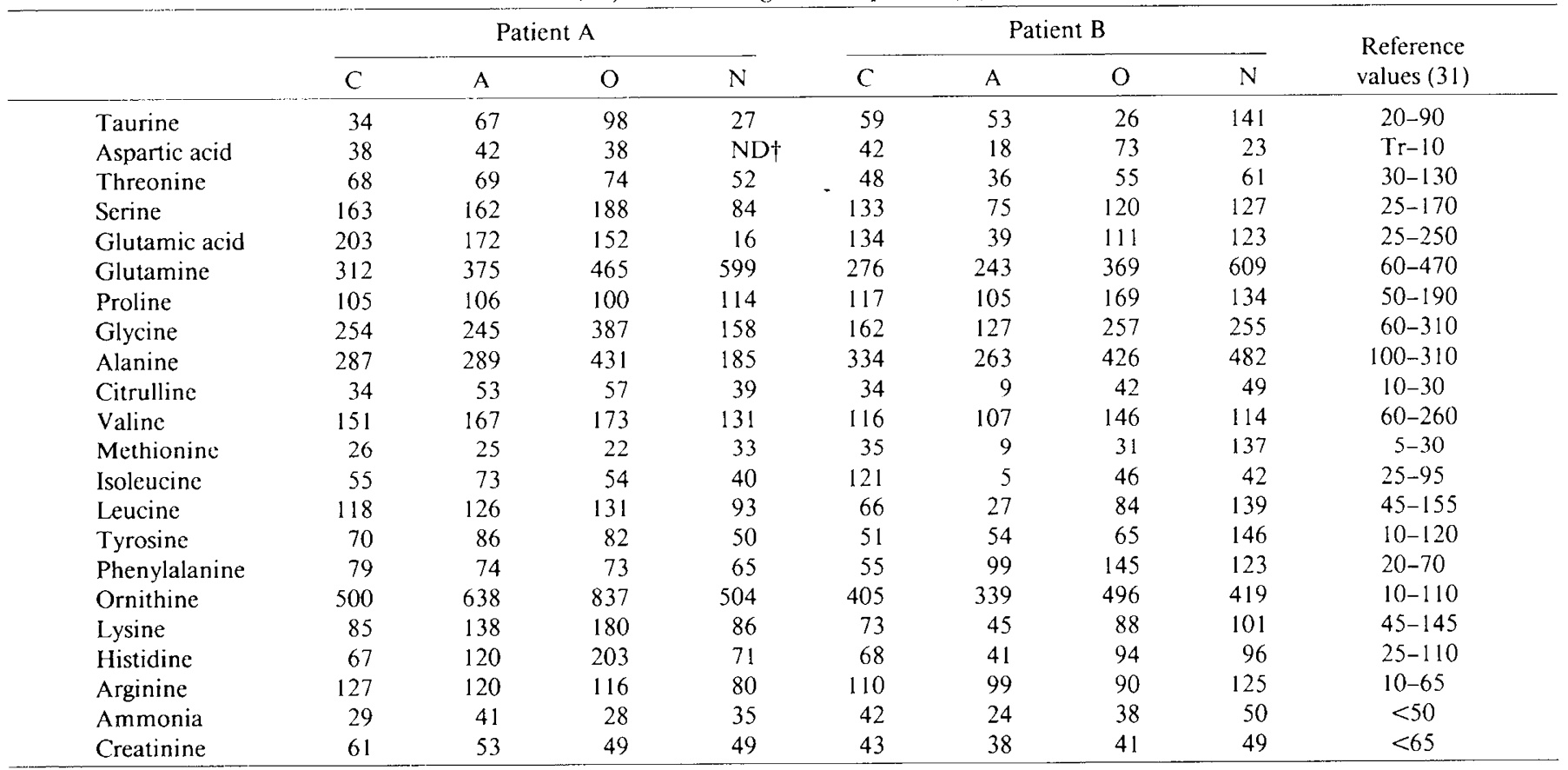

${ }^{*} \mathrm{C}, \mathrm{A}, \mathrm{O}, \mathrm{N}$, after $2 \mathrm{wk}$ of supplement with citrulline (C), arginine (A), or ornithine (0) $2 \mathrm{mmol} / \mathrm{kg}$ body weight per day or no supplement (N).

$\dagger$ Not detectable. 
Table 2. Urinary excretion of amino acids, orotic acid ( $\mu \mathrm{mol} / \mathrm{mol}$ creatinine), creatine, creatinine ( $\mu \mathrm{mol} / \mathrm{kg}$ body wt per day) and urea (mmol/kg body wt per day) in patients $A$ and $B$

\begin{tabular}{|c|c|c|c|c|c|c|c|c|c|}
\hline & \multicolumn{4}{|c|}{ Patient A } & \multicolumn{4}{|c|}{ Patient B } & \multirow{2}{*}{$\begin{array}{c}\text { Reference values } \\
(29,32,33)\end{array}$} \\
\hline & $C^{*}$ & $\mathrm{~A}$ & $\mathrm{O}$ & $\mathrm{N}$ & $\mathrm{C}$ & A & $\mathrm{O}$ & $\mathrm{N}$ & \\
\hline Taurine & 20 & 14 & 10 & 26 & 44 & 56 & 20 & 72 & \\
\hline Aspartic acid & 2 & $\mathrm{ND}+$ & 8 & ND & 13 & 6 & 5 & 9 & \\
\hline Threonine & 11 & 23 & 17 & 10 & 23 & 11 & 6 & 18 & $<100$ \\
\hline Serine & 44 & 75 & 64 & 27 & 73 & 30 & 13 & 63 & $<340$ \\
\hline Glutamic acid & 8 & 9 & 22 & 44 & 6 & 4 & 24 & 18 & \\
\hline Proline & 2 & 3 & 2 & ND & 1 & 1 & 2 & 9 & $<25$ \\
\hline Glycine & 100 & 169 & 140 & 85 & 230 & 258 & 225 & 372 & $<500$ \\
\hline Alanine & 57 & 124 & 105 & 53 & 153 & 208 & 154 & 174 & $<190$ \\
\hline Citrulline & 217 & 38 & 27 & 2 & 1349 & 67 & 42 & ND & \\
\hline Valine & 9 & 13 & 11 & 7 & 29 & 28 & 16 & 18 & $<22$ \\
\hline Cystine & 9 & 13 & 12 & 7 & 43 & 38 & 34 & 9 & $<55$ \\
\hline Isoleucine & 0.1 & 0.1 & 0.1 & 4 & 2 & 12 & 3 & 45 & $<25$ \\
\hline Leucine & 0.1 & 9 & 7 & 5 & 10 & 60 & 17 & 45 & $<20$ \\
\hline Phenylalanine & 8 & 17 & 19 & 10 & 12 & 18 & 9 & 30 & $<35$ \\
\hline Ornithine & 75 & 310 & 260 & 37 & 205 & 580 & 482 & 42 & $<13$ \\
\hline Lysine & 22 & 87 & 55 & 12 & 76 & 99 & 61 & 33 & $<120$ \\
\hline Histidine & 94 & 191 & 173 & 91 & 179 & 194 & 158 & 219 & $<320$ \\
\hline Arginine & 78 & 60 & 20 & 7 & 214 & 156 & 27 & 6 & $<7$ \\
\hline Homocitrulline & 27 & 75 & 34 & 95 & 34 & 59 & 16 & 78 & \\
\hline Orotic acid & 139 & 132 & 7.13 & 172 & 34 & 71 & 254 & 79 & $0.08-0.44$ \\
\hline Creatine & 97 & 114 & 57 & 21 & 105 & 65 & 25 & 11 & $41-104$ \\
\hline Urea & 5.3 & 5.8 & 4.8 & 4.1 & 6.1 & 3.9 & 3.4 & 2.6 & \\
\hline Creatinine & 145 & 138 & 152 & 130 & 137 & 112 & 114 & 97 & $88-132$ \\
\hline
\end{tabular}

* For abbreviations see Table 1 .

$\dagger$ Not detectable.

As shown in Table 2 marked variations in orotic acid excretion were observed in both patients with the different protocols. In patient A orotic acid was lowest with ornithine supplement, while in patient B the lowest orotic acid excretion was achieved with citrulline and the highest occurred with ornithine supplement. The increase in orotic acid was not associated with an increase of homocitrulline excretion or with the elevation of ornithine in plasma.

\section{DISCUSSION}

The clinical histories of our patients show that in contrast to previous descriptions $(1-12,14)$ patients with $\mathrm{HHH}$ syndrome can also present with neonatal onset. The syndrome should thus be included in the differential diagnosis of neonatal hyperammonemias. Because of the difficulty to detect small amounts of homocitrulline in urine in the first days of life the HHH syndrome may be confused at the beginning with an OCT deficiency (patient B, 13).

Our study was aimed at testing chronic treatment not acute loads. Because of the good clinical condition we did not consider it to be ethically acceptable to challenge the patients with protein to such an extent that hyperammonemia would occur. Nevertheless the biochemical changes are of interest. A novel finding is the lower creatine excretion in our patients when not supplemented with arginine or citrulline.

The rate limiting enzyme for creatine formation is amidinotransferase (EC 2.1.4.1) catalyzing the formation of guanidino acetate and ornithine from arginine and glycine. The enzyme is mainly found in kidney and pancreas (22). Two isoenzymes have been isolated. Product inhibition of ornithine appears to be relevant in vivo (23-25) as exemplified by Sipilä (24). If $\mathrm{HHH}$ syndrome is really due to a transport defect of ornithine into the mitochondrion, the low creatine excretion (reflecting its limited formation) could well be due to the inhibition of the amidinotransferase by increased ornithine in the cytosol and in the intermembrane space. The effect appears to be at least partly reversed by increasing the substrate arginine (direct supplementation or through conversion from citrulline). The correlation with urea excretion and low plasmatic glycine values are compatible with such an interpretation. If ornithine leads to product inhibition of transamidinase in $\mathrm{HHH}$ patients and if ornithine is depleted in the mitochondria then one would have to conclude that in man the amidinotransferase is not located in the mitochondrial matrix as in chicken (26), and as assumed by Sipilä for $\mathrm{HHH}$ patients (24). Our data suggest that in man the amidinotransferase could perhaps be located at the external side of the inner mitochondrial membrane as found in the rat (27), in the intermembrane space, on the external membrane, or in the cytosol. Additional work is needed for definitive proof.

In contrast to ornithine supplement the addition of arginine or citrulline to the diet appears to reduce the ammonia load to the patients as manifest by the lowered plasma glutamine. This is in accordance with the findings of Simell et al. (9) showing the ineffectiveness of ornithine in preventing hyperammonemia after alanine load. It is in contrast to the report of Kirsch and McInnes (12) who found the chronic application of ornithine- $\mathrm{HCl}$ to be helpful in controlling hyperammonemia. It cannot be ruled out that in the latter treatment not the ornithine but the $\mathrm{HCl}$ moiety was effective. Chronic acidosis is well known to stimulate renal ammonia excretion by activating the glutaminase. $\mathrm{HCl}$ administration has actually been used in treatment of mild OCT deficiency (28). Citrulline substitution appears to be preferable to arginine supplement in view of the reduction of tubular lysine reabsorption by arginine application. However, the loss of lysine with arginine supplement was not such as to lead to low plasma carnitine. Another reason for substituting citrulline instead of arginine is that it allows the detoxication of one aspartate nitrogen to urea.

A puzzling finding in our and in some patients reported in the literature is that plasma citrulline concentrations are normal or even elevated while orotic acid excretion is increased $(3,6,9)$. 
This latter is found in hyperammonemia when carbamylphosphate accumulates and when aspartate is not decreased (29). In HHH syndrome this is thought to be due to ornithine depletion in the mitochondria with reduced flux through the OCT. However, this should lead to decreased citrulline production. One could speculate that argininosuccinate synthetase might be inhibited competitively by homocitrulline in the patients since homocitrulline has been shown to be a substrate for argininosuccinate synthetase (30).

In our patients homocitrulline excretion was almost as high with arginine supplement as without treatment, while citrulline and ornithine application led to lower homocitrulline output. We thus wonder if the guanidino group of arginine might be a precursor of the homocitrulline (and even citrulline) in $\mathrm{HHH}$ syndrome the acceptor substrate being lysine or a metabolite of this aminoacid.

One of our patients (B) was additionally affected by a factor VII and X deficiency. This has been reported in two other patients with $\mathrm{HHH}$ syndrome $(3,9)$. One thus could suspect that the genetic defect is located on the long arm of chromosome 13. Delimiting the defect of $\mathrm{HHH}$ syndrome at the DNA level might help in the future to establish conclusively the cause of $\mathrm{HHH}$ syndrome.

Acknowledgments. The authors thank Dr. K. Lauber, Mrs. M. Kokorovic, M. Gradwohl, and U. Pfister for their technical assistance.

\section{REFERENCES}

1. Shih VE, Efron ML, Moser HW 1969 Hyperornithinemia, hyperammonemia and homocitrullinuria. A new disorder of amino acid metabolism associated with myoclonic seizures and mental retardation. Am J Dis Child 117:83-92

2. Wright T, Pollit R 1973 Psychomotor retardation, epileptic and stuporous attacks, irritability and ataxia associated with ammonia intoxication, high blood ornithine levels and increased homocitrulline in the urine. Proc R Soc Med 66:221

3. Gatfield PD, Taller E, Wolfe DM, Haust MD 1975 Hyperornithinemia, hyperammonemia and homocitrullinuria associated with decreased carbamyl phosphate synthetase I activity. Pediatr Res 9:448-497

4. Sabetta G, Lombardi M, Castro M, Scapaticci A, Giampaolo R, D'Ippoliti M, Lucidi V 1980 Iperammoniemia, iperornitinemia omocitrullinuria:descrizione di un caso. Agg Pediatr 31:479-482

5. Winter MS, Perez-Atayade AR, Levy ML, Shih VE 1980 Unique hepatic ultrastructural changes in a patient with hyperornithinemia, hyperammonemia and homocitrullinuria. Pediatr Res 14:583 (abstr)

6. Hommes FA, Ho CK, Roesel RA, Coryell HE, Gordon BA 1982 Decreased transport of ornithine across the inner mitochondrial membrane as a cause of hyperornithinemia. J Inherited Metab Dis 5:41-47

7. Oyanagi K. Tsuchiyama A Itakura Y, Sogawa H, Wagatsuma K. Nakao T Sakamoto S, Yachi A 1983 The mechanism of hyperammonemia and hyperornithinemia in the syndrome of hyperornithinemia, hyperammonemia with homocitrullinuria. J Inherited Metab Dis 6:133-134

8. Otten A, Buerger U. Bachmann C, Hillig U, Wolf H 1984 Late diagnosis of and therapeutical approach to the $\mathrm{HHH}$ syndrome. In: Abstracts of the Third International Symposium on Inborn Error of Metabolism in Humans. March 7-9, Munich. Karger, Basel, p 102

9. Simell O, Mackenzic S, Clow CL, Scriver CR 1985 Ornithine loading did not prevent induced hyperammonemia in a patient with hyperornithinemiahyperammonemia-homocitrullinuria syndrome. Pediatr Res 19:1283-1287

10. Hommes FA, Roesel RA, Metoki K. Hartlage PL, Dyken PR 1986 Studies on a case of $\mathrm{HHH}$ syndrome (hyperammonemia, hyperornithinemia, homocitrullinuria). Neuropediatrics 17:48-52
11. Gjessing LR, Lunde HA, Undrum T, Broch H, Alme A, Lie SO 1986 A new patieni with hyperornithinemia, hyperammonemia and homocitrullinuria treated early with low protein diet. J Inherited Metab Dis 9:186-192

12. Kirsch SE. McInnes RR 1986 Control of hyperammonemia in the $3 \mathrm{H}$ syndrome by ornithine administration. Pediatr Res 20:267(abstr)

13. Haass C, Pedicino R, Sabetta G, Panero A. Colarizzi P 1986 Hyperornithinemia, hyperammonemia and homocitrullinuria (HHH syndrome) with neonatal onset and favourable evolution. Ital J Pediatr 12:143-146

14. Rodes M, Ribes A, Pineda M, Alvarez L, Fabregas I, Fernandez Alvarez E. Coude FX, Grimber G 1987 A new family affected by the syndrome of hyperornithinemia, hyperammonemia and homocitrullinuria. $J$ Inherited Metab Dis 10:73-81

15. Fell V Pollit RJ, Sampson GA, Wright T 1974 Ornithinemia, hyperammonemia and homocitrullinuria: a disease associated with mental retardation and possibly caused by defective mitochondrial transport. Am J Dis Child 127:752-756

16. Gray RGF. Hill SE, Pollit RJ 1982 Reduced ornithine catabolism in cultured fibroblasts and phytohemagglutinin-stimulated lymphocytes from a patient with hyperornithinemia, hyperammonemia and homocitrullinuria. Clin Chim Acta 118:141-148

17. Shih VE, Mandell R. Herzfeld A 1982 Defective ornithine metabolism in cultured skin fibroblasts from patients with the syndrome of hyperornithinemia, hyperammonemia and homocitrullinuria. Clin Chim Acta 118:149157

18. Gray RGF. Hill SE. Pollit RJ 1983 Studies on the pathway from ornithine to proline in cultured skin fibroblasts with reference to the defect in hyperornithinemia with hyperammonemia and homocitrullinuria. J Inherited Metab Dis 6:143-148

19. Gordon BA. Gatfield PD. Wolfe DM 1976 Studies on the metabolic defect in patients with hyperammonemia. hyperornithinemia and homocitrullinuria. Clin Res 24:668 (abstr)

20. Bachmann C Colombo JP 1980 Determination of orotic acid in children's urine. J Clin Chem Clin Biochem 18:293-295

21. Lauber K 1966 Bestimmung von Kreatin in Serum and Urin. Z Klin Chem 4:119-122

22. Methfessel J 1976 Zur Organ- und Subzellularvertcilung der Transamidinase bei Mensch and Ratte. Acta Biol Med Germ 35:309-315

23. Sipilä I, Simell O. Arjomaa P 1980 Gyrate atrophy of the choroid and retina with hyperornithinemia: deficient formation of guanidinoacetic acid from arginine. J Clin Invest 66:684-687

24. Sipilä I 1980 Inhibition of arginine-glycine amidinotransferase by ornithine: a possible mechanism for the muscular and chorioretinal atrophies in gyrate atrophy of the choroid and retina with hyperornithinemia. Biochim Biophys Acta 613:79-84

25. Walker JB 1979 Creatine: biosynthesis, regulation and function. Adv Enzymo $50: 177-242$

26. Grazi E. Magri E. Balboni G 1975 On the control of arginine metabolism in chicken kidney and liver. Eur J Biochem 60:431-436

27. Magri E, Balboni G, Grazi E 1975 On the biosynthesis of creatine: intramitochondrial localisation of transamidinase from rat kidney. FEBS Lett 55:9193

28. Zimmermann A. Bachmann C. Colombo JP 1981 Ultrastructural pathology in congenital defects of the urea cycle: ornithine transcarbamylase and carbamylphosphate synthetase deficiency. Virchows Arch 393:321-331

29. Bachmann C. Colombo JP 1980 Diagnostic value of orotic acid excretion in heritable disorders of the urea cycle and in hyperammonemia due to organic acidurias. Eur J Pediatr 134:109-113

30. Rochovansky O Ratner S 1967 Biosynthesis of urea. XII. Further studies on argininosuccinate synthetase: substrate affinity and mechanism of action. J Biol Chem 242:3839-3849

31. Bremer HJ. Duran M, Kamerling JP. Przyrembel H, Wadman SK 1981 Normal values. In: Disturbances of Amino Acid Metabolism: Clinical Chemistry and Diagnosis. Urban and Schwarzenberg. Baltimore, pp 181-227

32. Pavry P. Huang Y, Kamoun P 1979 Age related reference values for urinary free amino acids: a simple method of evaluation. J Clin Chem Clin Biochem 17:205-210

33. Sherwin JE Natelson S 1977 Creatine and creatinine coefficients. In: Mcites S (ed) Pediatric Clinical Chemistry. American Association for Clinical Chemistry Inc, Washington DC, pp 89--90 